\title{
Phosphorus sources, bioavailability, and cycling in the Murderkill River, Delaware
}

\author{
MARGARET S. MUSSER ${ }^{1 *}$, DEB P. JAISI ${ }^{1}$ \\ ${ }^{1}$ Department of Plant and Soil Sciences, University of \\ Delaware, Newark, DE 19716, USA ( ${ }^{*}$ correspondence: \\ msmuss@udel.edu)
}

Excess phosphorus (P) is a major cause of water quality degradation and eutrophication worldwide. While the Delaware Bay overall is less prone to eutrophication, one of its sub-estuaries, the Murderkill Watershed, has experienced historically high P influx and seasonal eutrophic conditions. Here we sampled different forms of $\mathrm{P}$ from the Murderkill Watershed, including soil-P from agricultural, residential, and forested land, effluent-P from the wastewater treatment facility within the Murderkill River, and dissolved and particulate-P in the Murderkill River itself in midSeptember. Historical data from Delaware Natural Resource and Environmental Control (DNREC) and USGS reports September averages of inorganic $\mathrm{P}\left(\mathrm{P}_{\mathrm{i}}\right)$ concentrations ranging $0.6-6 \mu \mathrm{M}$ within the freshwater and tidal portions of the Murderkill River for more than a decade. $P_{i}$ concentration data from this study falls within the bounds of the historical range. Despite natural $P$ fluctuations, $\mathrm{P}_{\mathrm{i}}$ concentration is decreasing at the confluence with the wastewater treatment facility.

Additionally, among different soil $\mathrm{P}$ pools, the highest concentration of $\mathrm{P}_{\mathrm{i}}$ is found in the $\mathrm{NaOH}-\mathrm{P}$ pool across soils from three different land-uses - forested, agricultural, and residential-in the Murderkill watershed. Agricultural soils have the highest $\mathrm{P}$ content overall. Phosphate oxygen isotope $\left(\delta^{18} \mathrm{O}_{\mathrm{P}}\right)$ analysis is applied to water, soil, and particulate matter to identify potential sources of $\mathrm{P}$ in the Murderkill watershed. Identifying the particular sources or processes of $\mathrm{P}$ abatement is crucial to mitigating water quality concerns and to avoid exceeding the Murderkill River's TMDL. 